\title{
Regional Differences in Warfarin Therapy Among Japanese Patients With Atrial Fibrillation
}

\author{
Yasushi Miyauchi, MD
}

$\mathbf{I}$ t has been reported that warfarin therapy for patients with atrial fibrillation (AF), including its usage frequency, quality of control, and effectiveness, varies from region to region, particularly between Asian and non-Asian countries, ${ }^{1-3}$ and between Japan and other East Asian countries. ${ }^{4}$ Such regional differences may be caused by many environmental factors such as geographic conditions, patients' lifestyle including their food and drink, ${ }^{5}$ socioeconomic background, medical conditions, ${ }^{6}$ as well as genetic factors. ${ }^{7,8}$ Statistics provided by the Japanese government show considerable differences in the profiles of the risk factors, medical conditions, ${ }^{9}$ and lifestyles among various regions in Japan. ${ }^{10}$ The annual rate of admission or hospital/clinic visits for cerebral infarctions in 2008 in 47 administrative divisions ${ }^{9}$ are shown in Figure 1. Generally, the incidence was lower in urban divisions in Southern Kanto, Chubu, and Kansai, as opposed to a higher incidence in Shikoku, Kyushu, and Hokkaido. Therefore, it is of great interest whether there are also any such regional differences in the clinical characteristics, frequency and quality of warfarin treatment, and its outcome in Japanese patients with AF.

\section{Article p 1548}

In this issue of the Journal, Inoue et $\mathrm{al}^{11}$ elucidate the differences among 10 geographic regions in Japan regarding the clinical background, frequency, and intensity of warfarin therapy, and its outcome in 7,406 patients with non-valvular AF enrolled in the J-RHYTHM registry. The patients were enrolled between January 2009 and July 2009 when warfarin was the only available oral anticoagulant. They found significant regional differences in various clinical characteristics including the age, sex, type of AF, comorbidities, risk factors for stroke, and usage of various drugs. The $\mathrm{CHADS}_{2}$ score was highest in Shikoku (2.1 \pm 1.3$)$, followed by Kyushu and Chubu (1.8 \pm 1.3$)$, and was lowest in Southern Kanto (1.5 \pm 1.2$)$ (Figure 2A). The frequency of warfarin use was consistently high throughout the regions (79.3-94.4\%), though there were significant regional differences $(\mathrm{P}<0.001$, Figure 2B). There were modest but significant differences in the time in the therapeutic range (TTR) values (57.7-62.2\%) among the regions (Figure 2C). The incidence of thromboembolic events differed significantly among the regions, and occurred most frequently in Shikoku (3.6\%/2 years), followed by Northern Kanto (2.9\%/2 years) and Hokkaido (2.5\%/2 years), and occurred least frequently in Hokuetsu $(0.3 \% / 2$ years) followed by Kansai ( $0.7 \% / 2$ years) (Figure 2D). Because the frequency of warfarin use, patient's age, and a history of stroke or transient ischemic attack were significant factors for thromboembolic events, a higher incidence in Shikoku and a lower incidence in Hokuetsu and Tohoku can be partly explained by the frequency of warfarin use and the $\mathrm{CHADS}_{2}$ score. However, region was still a significant independent factor of thromboembolic events even after adjustment by these clinical factors. The adjusted hazard ratios for thromboembolic events were 0.12 in Hokuetsu, 0.26 in Kansai, and 0.28 in Tohoku when Shikoku was set as the reference (Figure 2E).

Some caution is heeded when interpreting these results. As demonstrated in Figure 1, the incidence of cerebral infarction differed even among the administrative divisions in Hokuetsu (higher in Niigata and Toyama and lower in Fukui) and

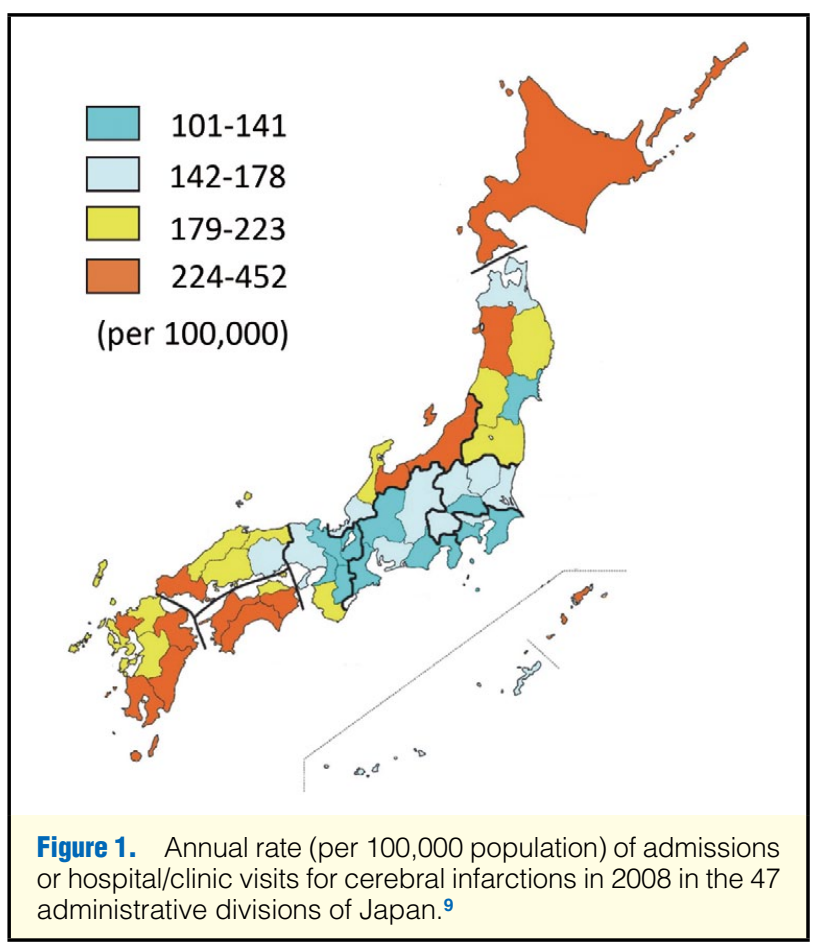

The opinions expressed in this article are not necessarily those of the editors or of the Japanese Circulation Society.

Received May 23, 2016; accepted May 23, 2016; released online June 3, 2016

Division of Cardiology, Department of Internal Medicine, Nippon Medical School Chiba-Hokuso Hospital, Inzai, Japan

Mailing address: Yasushi Miyauchi, MD, Division of Cardiology, Department of Internal Medicine, Nippon Medical School Chiba-Hokuso

Hospital, 1715 Kamagari, Inzai 270-1694, Japan. E-mail: miyauchi@nms.ac.jp

ISSN-1346-9843 doi:10.1253/circj.CJ-16-0505

All rights are reserved to the Japanese Circulation Society. For permissions, please e-mail: cj@j-circ.or.jp 


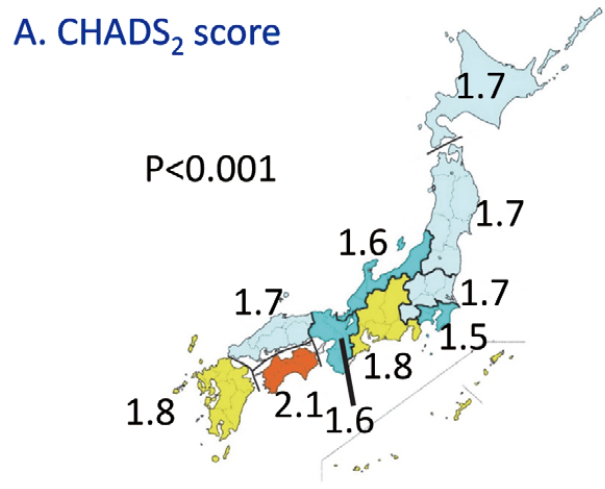

\section{Thromboembolic events (\% / 2 years)}

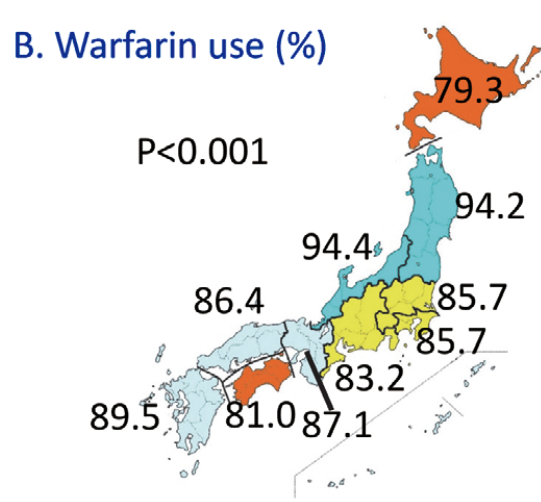

C. Mean TTR (\%)

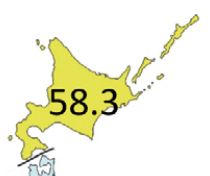

\section{E. Adjusted hazard ratio for thromboembolic events}

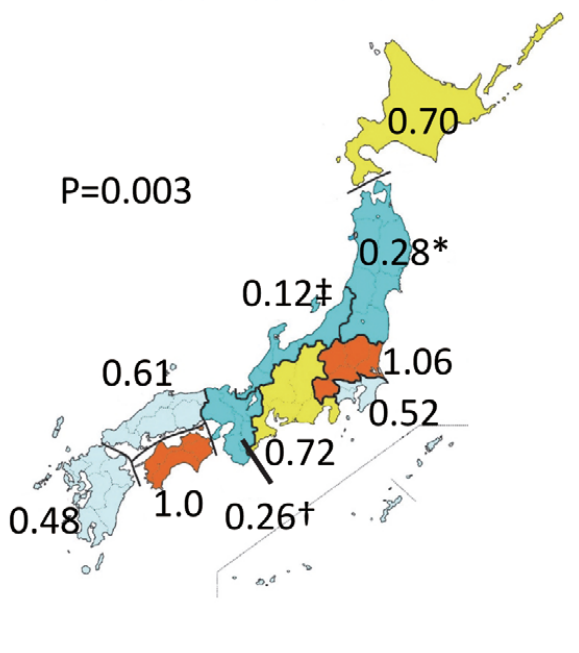

Figure 2. Mean $\mathrm{CHADS}_{2}$ score (A), frequency of warfarin use (B), mean time in the therapeutic range (TTR) (C), frequency of thromboembolic events (D), and the adjusted hazard ratio for thromboembolic events (E) in the 10 regions of Japan. ${ }^{*} P=0.010$ vs. Shikoku, ${ }^{\dagger} \mathrm{P}=0.003$ vs. Shikoku, $\neq \mathrm{P}=0.007$ vs. Shikoku. (Reproduced from Inoue H, et al ${ }^{11}$ by the author.)

Tohoku (higher in Akita and lower in Miyagi) in the national database. If the study patients were not evenly distributed in this region, they may not have been representative of the region. Because the number of study sites and patients were relatively small in Hokuetsu, this limitation may be applicable to this region as the authors mention. Further, the patients included in this study were treated in some highly specialized institutions and may not have represented the general population of the region. In fact, the frequency of warfarin use (79.3-94.4\%) was much higher than that in the Fushimi AF Registry $(53.1 \%),{ }^{12}$ a community-based survey conducted in an urban area. It seems difficult to perform such communitybased surveys covering the whole nation. However, analyses of a recently available medical insurance database may give us the true frequency of warfarin use and the thromboembolic event rates in patients with $\mathrm{AF}$ region by region in the near future.

Nevertheless, this study derived from a nationwide registry is quite important because it clearly showed regional differences in the risk factors for thromboembolic events, frequency, and intensity of warfarin therapy and its outcome in Japanese patients with AF for the first time. Region was an independent factor for thromboembolic events. Therefore, what caused the differences even after adjusting for other factors? As the authors mentioned, some unknown confounding factors such as a difference in the thromboplastin reagent used may account for regional differences. In fact, when a thromboplastin reagent with a high international sensitivity index is 
used, the variation in the international normalized ratio (INR) values becomes larger as the PT-INR increases. Other possible factors include consumption of food and drink that may affect warfarin activity and risk factors, which differed among the regions..$^{10}$ Genetic factors affecting anticoagulation ${ }^{13}$ may vary among the regions, even though Japanese are considered genetically homogeneous. ${ }^{7}$ Future studies are expected to elucidate the true regional differences in warfarin therapy and the mechanisms underlying these differences.

\section{References}

1. Yamashita T, Koretsune Y, Yang Y, Chen SA, Chung N, Shimada YJ, et al. Edoxaban vs. warfarin in East Asian patients with atrial fibrillation: An ENGAGE AF-TIMI 48 subanalysis. Circ J 2016; 80: 860-869.

2. Wong KS, Hu DY, Oomman A, Tan RS, Patel MR, Singer DE, et al. Rivaroxaban for stroke prevention in East Asian patients from the ROCKET AF trial. Stroke 2014; 45: 1739-1747.

3. Huisman MV, Rothman KJ, Paquette M, Teutsch C, Diener HC, Dubner SJ, et al. Antithrombotic treatment patterns in patients with newly diagnosed nonvalvular atrial fibrillation: The GLORIA-AF Registry, phase II. Am J Med 2015; 128: 1306-1313.e1, doi: 10.1016/j.amjmed.2015.07.013.

4. Shimada YJ, Yamashita T, Koretsune Y, Kimura T, Abe K, Sasaki $\mathrm{S}$, et al. Effects of regional differences in Asia on efficacy and safety of edoxaban compared with warfarin: Insights from the ENGAGE AF-TIMI 48 Trial. Circ J 2015; 79: 2560-2567.

5. Chan HT, So LT, Li SW, Siu CW, Lau CP, Tse HF. Effect of herbal consumption on time in therapeutic range of warfarin therapy in patients with atrial fibrillation. J Cardiovasc Pharmacol 2011; 58:
87-90.

6. Meadows TA, Bhatt DL, Cannon CP, Gersh BJ, Rother J, Goto S, et al. Ethnic differences in cardiovascular risks and mortality in atherothrombotic disease: Insights from the Reduction of Atherothrombosis for Continued Health (REACH) registry. Mayo Clin Proc 2011; 86: $960-967$.

7. Yi S, An H, Lee H, Lee S, Ieiri I, Lee Y, et al. Korean, Japanese, and Chinese populations featured similar genes encoding drug-metabolizing enzymes and transporters: A DMET Plus microarray assessment. Pharmacogenet Genomics 2014; 24: 477-485.

8. Golwala H, Jackson LR 2nd, Simon DN, Piccini JP, Gersh B, Go AS, et al. Racial/ethnic differences in atrial fibrillation symptoms, treatment patterns, and outcomes: Insights from Outcomes Registry for Better Informed Treatment for Atrial Fibrillation Registry. Am Heart J 2016; 174: 29-36.

9. Minitry of Health, Labour, and Welfare. Basic statistics of regional health and medical care (in Japanese). 2009. http://www.mhlw.go.jp/ toukei/saikin/hw/hoken/kiso/21.html (accessed May 13, 2016).

10. Statistics Bereau, Ministry of Internal Affairs. Statistics of family budget (in Japanese). 2015. http://www.stat.go.jp/data/kakei/5.htm (accessed May 15, 2016).

11. Inoue $\mathrm{H}$, Atarashi $\mathrm{H}$, Kodani $\mathrm{E}$, Okumura $\mathrm{K}$, Yamashita $\mathrm{T}$, Origasa $\mathrm{H}$, et al; on behalf of the J-RHYTHM Registry Investigators. Regional differences in frequency of warfarin therapy and thromboembolism in Japanese patients with non-valvular atrial fibrillation: Analysis of the J-RHYTHM Registry. Circ J 2016; 80: 1548-1555.

12. Akao M, Chun YH, Esato M, Abe M, Tsuji H, Wada H, et al. Inappropriate use of oral anticoagulants for patients with atrial fibrillation. Circ J 2014; 78: 2166-2172.

13. Park YK, Lee MJ, Kim JH, Kim SJ, Kim JS, Lee SY, et al. Lack of association of clinical factors (SAMe-TT2R2) with CYP2C9/ VKORC1 genotype and anticoagulation control quality. I Stroke 2015; 17: 192-198. 